\title{
Article
}

\section{Toxic Effects of Heavy Metals and Organic Polycyclic Aromatic Hydrocarbons in Sediment Porewater on the Amphipod Hyalella azteca and Zebrafish Brachydanio rerio Embryos from Different Rivers in Taiwan}

\author{
Shao-Yang Hu ${ }^{1}{ }^{\mathbb{D}}$, Chi-Ying Hsieh ${ }^{2, *}$, Hans-Uwe Dahms ${ }^{3,4,5, * \mathbb{D},}$, Yu-Hsien Tseng ${ }^{2}$, Jesse Chen ${ }^{1}$, \\ Meng-Chun $\mathrm{Wu}^{2}$, Jin-Hyoung $\mathrm{Kim}^{6}$ and Cheng-Han Liu ${ }^{3}$
}

Citation: Hu, S.-Y.; Hsieh, C.-Y.; Dahms, H.-U.; Tseng, Y.-H.; Chen, J.; Wu, M.-C.; Kim, J.-H.; Liu, C.-H. Toxic Effects of Heavy Metals and Organic Polycyclic Aromatic Hydrocarbons in Sediment Porewater on the Amphipod Hyalella azteca and Zebrafish Brachydanio rerio Embryos from Different Rivers in Taiwan. Appl. Sci. 2021, 11, 8021. https://doi.org/ 10.3390/app11178021

Academic Editor: Simone Morais

Received: 23 July 2021

Accepted: 26 August 2021

Published: 30 August 2021

Publisher's Note: MDPI stays neutral with regard to jurisdictional claims in published maps and institutional affiliations.

Copyright: (c) 2021 by the authors. Licensee MDPI, Basel, Switzerland. This article is an open access article distributed under the terms and conditions of the Creative Commons Attribution (CC BY) license (https:// creativecommons.org/licenses/by/ $4.0 /)$.
1 Department of Biological Science and Technology, National Pingtung University of Science and Technology, Pingtung 91201, Taiwan; syhu@mail.npust.edu.tw (S.-Y.H.); jesseokta@hotmail.com (J.C.)

2 Department of Environmental Science and Engineering, National Pingtung University of Science and Technology, Pingtung 91201, Taiwan; aggfds861117@gmail.com (Y.-H.T.); light3712@gmail.com (M.-C.W.)

3 Department of Biomedical Science and Environmental Biology, KMU-Kaohsiung Medical University, Kaohsiung 80708, Taiwan; michaelliu103023055@gmail.com

4 Research Center for Environmental Medicine, KMU_Kaohsiung Medical University, Kaohsiung 80708, Taiwan

5 Department of Marine Biotechnology and Resources, National Sun-Yat-sen University, Kaohsiung 80424, Taiwan

6 Division of Life Sciences, Korea Polar Research Institute, Incheon 21990, Korea; kimjh@kopri.re.kr

* Correspondence: chiying@mail.npust.edu.tw (C.-Y.H.); hudahms11@gmail.com (H.-U.D.); Tel.: +886-8-770-3202 (ext. 7089) (C.-Y.H.); +886-7-312-1101 (ext. 2695) (H.-U.D.)

Abstract: The amphipod (Hyalella azteca) and zebrafish (Brachydanio rerio) embryos were used for toxicological sediment porewater testing. Porewaters from 35 sampling stations of eight streams in southern Taiwan were screened for toxic effects and their relationship with 6 metal and 16 polycyclic aromatic hydrocarbons (PAHs). Concentration analysis results showed that the following PAHs, naphththalene, benzo(b)fluoranthene, $\operatorname{dibenz}(\mathrm{a}, \mathrm{h})$ anthracene, acenaphthalene, and the heavy metal cadmium were not detected in 35 sampling stations. The highest detection rate of $94.1 \%$ was caused by the PAHs fluoranthene and pyrene. The highest detection rate of the metal zinc was $88.6 \%$ of 35 analyzed samples. The majority of samples (88\%) were classified as level tier 1 according to USEPA national sediment inventory. This indicates the probability of adverse effects on aquatic life or human health. The results of a zebrafish embryo test showed that heart rate and survival were significantly reduced with all porewater samples. Therefore, fish exposed to contaminated river conditions may be affected in their cardiovascular functions. Looking at correlations between toxic effects of metals and PAHs, we found that phenanthrene, anthracene, pyrene, benzo(a)anthracene, chrysene, benzo(b)fluoranthene, and benzo(a)pyrene were low, while fluorene was highly correlated with toxic effects of metals.

Keywords: river sediment pollution; trace metal; PAHs; toxic chemical; biomarker; circulatory function

\section{Introduction}

Sediments are deposits on the bottom of a water body and are naturally composed of sand, clay, soil, organic matter, and other minerals [1,2]. Sediments are also a sink, reservoir, and source of pollutants that harm natural water bodies and aquatic organisms [3-5]. Various chemical substances accumulate in sediments, which proves toxic effects on aquatic habitats and ecosystems [6]. Sediment porewater is defined as the water occupying the space between sediment particles which constantly remains in contact with sediments. Therefore, pollutants may be exchanged between sediment and porewater through dynamic equilibrium distribution [7]. Sediment particles are also where the benthic burrowing 
organisms depend on their livelihoods, so porewater is considered as an important toxic exposure pathway for benthic organisms [8], but chemical data can also directly provide relevant information for the interpretation of sediment toxicity data [6]. In recent years, porewater has become a valuable tool for evaluating the mobility, bioavailability, and toxicity of various pollutants [8-11].

Generally, indications provided from chemical analysis and biological exposure are used to evaluate whether-pollutants cause toxicity to organisms. Benthic communities are frequently used as indicators for watershed biomonitoring [12,13]. More recently, scientists studied the distribution and toxic effects of heavy metals and PAHs [14-20]. Micropollutants such as metals and organics can affect benthic communities by altering their physiology as well as their structure $[20,21]$. Polycyclic aromatic hydrocarbons (PAHs) are a class of the most important organic compounds containing stable aromatic rings as their molecular skeleton. They are lipophilic, carcinogenic, and have a tendency to adsorb to sediment particles [22-24]. They are not easy to degrade in the environment $[23,25]$. The main sources of PAH contamination are oil spills and hospital and municipal discharge. PAHs also accumulate in the organs of fish or other aquatic organisms, possibly with different affinities to different organs and tissues (e.g., the concentration of PAHs in gill may be greater than in muscle) [26,27]. This way, they are seriously endangering environmental integrity and human health. Approximately 130 PAHs have been identified [28]. The US EPA has classified 16 of the PAHs as priority-pollutants based on toxicity, their potential for human exposure, frequency of occurrence at hazardous waste sites, and the extent of information availability. These include: naphthalene, acenaphthylene, acenaphthene, fluorene, phenanthrene, anthracene, fluoranthene, pyrene, benzo[a]anthracene, chrysene, benzo[b]fluoranthene, benzo[k]fluoranthene, benzo[a]pyrene, benzo[g,h,i] perylene, indeno [1,2,3-c,d]pyrene, and dibenz[a,h]anthracene [29]. Among them, benzo(a)pyrene is currently regarded as most toxic according to the toxic equivalent quantity (TEQ) due to its highest potency in terms of carcinogenicity [30].

Metals and metalloids are collectively referred to as heavy metals [31]. Some heavy metals, also called trace metals (e.g., Mn, Fe, Co, Ni), are essential to organisms, while other heavy metals (e.g., $\mathrm{Cd}, \mathrm{Pb}$, and $\mathrm{Hg}$ ) are nonessential and usually toxic even in trace amounts [32]. These nonessential metals can be transferred to higher trophic levels through the food chain, and then they also provide potential risks to aquatic life and human health [33-35]. They are deposited and released into the receiving waters and become bioavailable through aquatic food chains and are possibly hazardous to fishes and other aquatic populations [36,37]. Often pollutant storage reservoirs may cause toxic effects on benthic aquatic organisms, because their growth, reproduction, feeding, and other behaviors are taking place in the sediment [5]. Therefore, benthic organisms are often used as bioindicators to reflect the overall effects caused by a mixture of pollutants [30]. In this study, the amphipod Hyalella azteca and zebrafish embryos were used as biological test species to screen the sediments of eight streams in the south of Taiwan by conducting a $48 \mathrm{~h}$ porewater acute toxicity test. At the same time, the concentrations of metals and PAHs were measured in order to understand the relationship between toxicological response and chemical analysis in an attempt to explore the level of sediment pollution.

\section{Materials and Methods}

\subsection{Sample Collection}

In this study, thirty-five sediment samples were collected from eight rivers located in southern Taiwan (Houjin river-HJ, Donggang river-DG, Yanyan river-YS, Sanye riverSY, Dianbao river-DB, Agongdian river-AGD, Wuluo river-WR, and Niuchou riverLK) (as shown in Figure 1). Approximately $10 \mathrm{~kg}$ of sediment was collected from each sampling site, centrifuged after collection to obtain porewater, and stored in a refrigerator at $4{ }^{\circ} \mathrm{C}$ for subsequent biological and chemical experiments. 


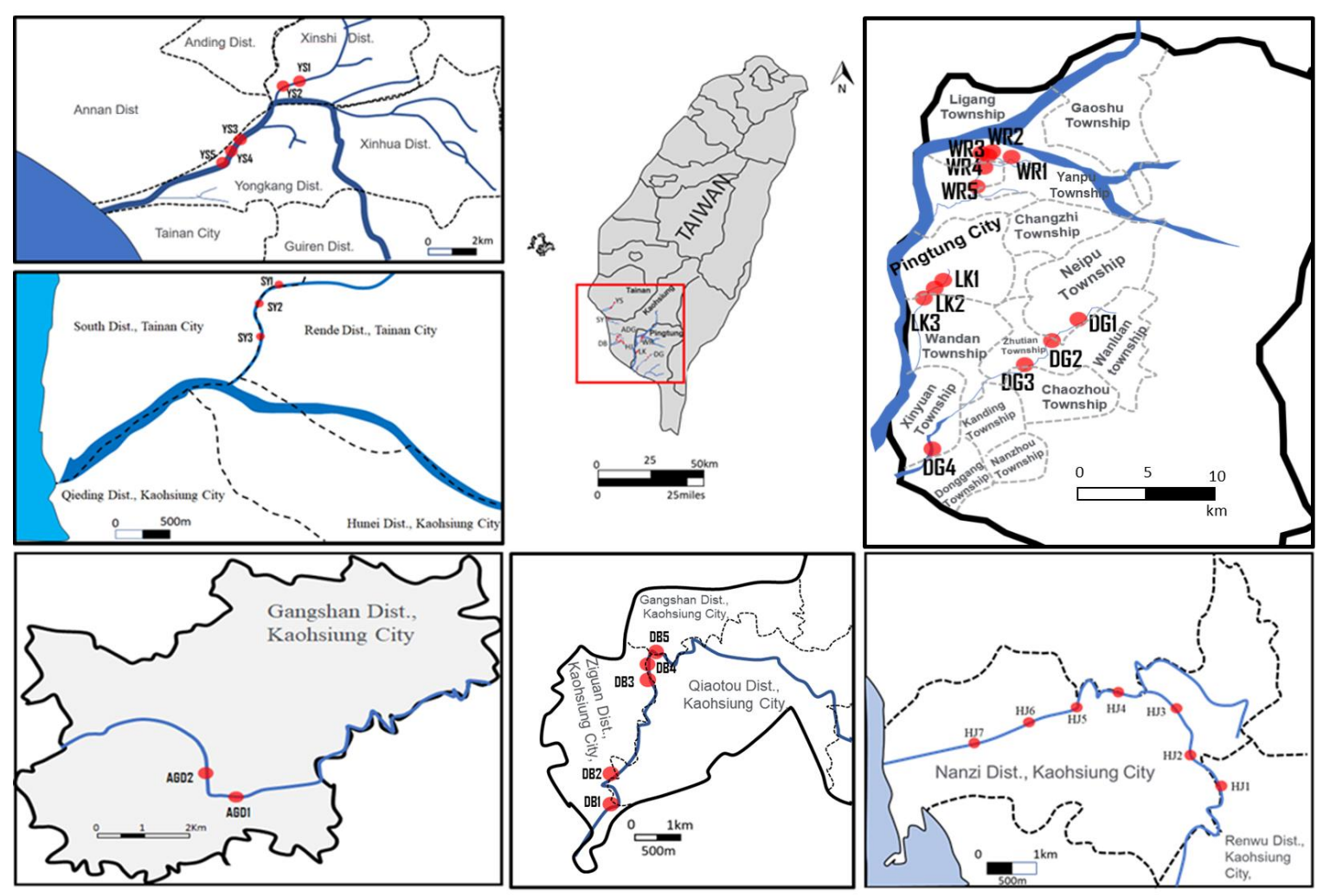

Figure 1. Sampling sites of riverine sediments in southern Taiwan.

\subsection{Sediment Porewater Toxicity Testing with the Amphipod Hyalella azteca}

Hyalella azteca is an epibenthic and phytal amphipod which plays a vital role in ecosystem resilience due to its detritus-feeding and potential high abundance in nature. It is widely distributed in the freshwaters of North America, South America, and the Caribbean. Algae, epiphytes, and sediment particles are the main food sources of this amphipod. It is about $3-8 \mathrm{~mm}$ long (males are larger than females) and considered to be sensitive to aquatic pollutants [38]. It is known to tolerate slight salinity changes, but not to survive $\mathrm{pH}$ conditions of less than 6.0.

Centrifuged porewater $(50 \mathrm{~mL})$ was obtained and kept at $4{ }^{\circ} \mathrm{C}$ until analysis. Water parameters such as $\mathrm{pH}$, conductivity, temperature, and dissolved oxygen were measured before and after this process at room temperature. Specimens of $H$. azteca, aged between 7 and 10 days, were selected to ensure that the test organisms were similar. H. azteca in reconstituted water $\left(96 \mathrm{mg} / \mathrm{L} \mathrm{NaHCO}_{3}, 30 \mathrm{mg} / \mathrm{L} \mathrm{MgSO}_{4}, 4 \mathrm{mg} / \mathrm{L} \mathrm{KCl}, 50 \mathrm{mg} / \mathrm{L} \mathrm{CaSO}_{4}\right.$, and $50 \mathrm{mg} / \mathrm{L} \mathrm{CaCl}_{2}$ were dissolved in deionized water and aerated vigorously for at least $24 \mathrm{~h}$ ) was used as controls. Operating conditions included a photoperiod of $16 \mathrm{~L}: 8 \mathrm{D}$, temperature $23 \pm 1{ }^{\circ} \mathrm{C}$, and $20 \mathrm{~mL}$ reconstituted water/sample volume. Samples were tested in duplicates of 10 test organisms per beaker and the controls were reconstituted waters following a standard method. Ten individuals were placed in a beaker for $48 \mathrm{~h}$ exposure, and their survival rates were compared. Differential survival with samples was then compared to the control $(80 \%)$ to estimate the level of toxicological risk.

In this study, after adjusting the results to the control group, samples with a relative survival rate of $<75 \%$ were defined as being toxic to organisms following US EPA suggestions $[39,40]$. The relative survival rate was obtained from the ratio of the observed survival rate of the sample organisms compared to the expected survival rate of the control group (Equation (1)).

$$
\text { Relative survival rate }=\frac{\text { Observed survival rate }}{\text { Expected survival rate }} \times 100
$$


It was suggested that if the adjusted survival rate of organisms was less than $75 \%$, this would cause adverse effects on aquatic organisms and human health. If the survival rate was between $75 \%$ and $90 \%$ for aquatic organisms, human health could be harmed, and if aquatic organisms showed a survival rate $>90 \%$, human health was certainly affected [40].

\subsection{Sediment Porewater Toxicity Testing with Zebrafish Embryos}

Mature wild zebrafish (AB strain wild type) were obtained from the Taiwan Zebrafish Core Facility at Academia Sinica (TZCAS). The experimental protocol was approved (approval no. NPUST-102-041) by the Institutional Animal Care and Use Committee (IACUC) of NPUST. Briefly, the zebrafish were raised at $28{ }^{\circ} \mathrm{C}$ in a circulating water tank. The photoperiod was set at 14/10 h light/dark cycle and mature wild zebrafish were fed with commercial ornamental fish food twice a day. The fertilized eggs obtained from the free spawning zebrafish were used for the assessment of developmental toxicity of the 35 porewater samples.

The one-cell stage of zebrafish fertilized eggs was evaluated for the toxicity of porewater and the experiment was carried out in 12-well plates. Thirty fertilized eggs of zebrafish were placed in each well containing $2 \mathrm{~mL}$ of aerated porewater samples. The porewater was refilled daily to record the survival rate, hatching rate, and deformity rate of zebrafish and the deformity pattern was observed using a dissecting microscope (Leica Z16-APO, Leica Microsystems Inc., Wetzlar, Germany). Fertilized eggs in aerated water (5.03 mM $\mathrm{NaCl}, 0.33 \mathrm{mM} \mathrm{MgSO} 4 \cdot 7 \mathrm{H}_{2} \mathrm{O}, 0.17 \mathrm{mM} \mathrm{KCl}$, and $0.33 \mathrm{mM} \mathrm{CaCl}_{2} \cdot 2 \mathrm{H}_{2} \mathrm{O}$ ) were dissolved in deionized water, aerated vigorously for at least $8 \mathrm{~h}$, and used as controls. Controls and all treatment groups were made in triplicate. The heartbeat rate of 6 hatched zebrafish per replicated treatment was evaluated on the third day as recorded by microscopic observation every minute. The experimental results were analyzed statistically by $t$-test and $p<0.05$ was regarded as significantly different.

\subsection{Analysis of Polycyclic Aromatic Hydrocarbons (PAHs)}

The porewater samples were filtered through a $0.22 \mu \mathrm{m}$ filter membrane (syringe filter, diameter $13 \mathrm{~mm}$, PVDF) which was followed by solid phase extraction (LiChrolut RP18 ${ }^{\circledR}$ $500 \mathrm{mg}$, $6 \mathrm{~mL}$ Merck, Darmstadt, Germany). Related to the concentration of the solvent, the PAHs concentration was measured by Ultra performance liquid chromatography (UPLC) (Waters, Milford, MA, USA) coupled with a photodiode array detector (PDA) and a fluorescence detector for analysis and quantification. The separation was carried out on a UPLC ${ }^{\circledR}$ BEH Shield RP18 $(2.1 \times 150 \mathrm{~mm}, 1.7 \mu \mathrm{m})$ column, with ultra-pure water and acetonitrile as the mobile phase for gradient elution. For acenaphthylene, the UV detector wavelength was set at $228 \mathrm{~nm}$. The elution conditions to separate the target compounds by fluorescence detection, and method detection limits (MDL) are shown as supplementary material (Tables S1-S3). The linear correlation coefficient (R) for all compounds was $>0.995$.

\subsection{Analysis of Trace Metals}

Sample pretreatment and analysis were followed by NIEA standard method (NIEA M353.01C). Porewater samples were filtered through cellulose acetate filters (pore diameter, $0.45 \mu \mathrm{m})$. The filtrate was acidified with $1 \%$ trace-metal grade nitric acid as a pre-treatment. The extracted portion was detected using an inductively coupled plasma optical emission spectrometer (ICP-OES, Optima 2100 Perkin-Elmer, Waltham, WA, USA) for Cr, Ni, Cu, Zn, $\mathrm{Pb}$, and $\mathrm{Cd}$ analysis.

2.6. Calculations of Porewater Toxicity by Interstitial Water Benchmark Units (IWBUs)/Interstitial Water Toxic Units (IWTU)

The pollutant distribution between the sediment and the porewater is expected to cause different toxic effects. It is not proper to restrict toxicity evaluation to either result. Therefore, interstitial water benchmark units (IWBUs) can be used to predict the toxic effects of various metals on aquatic organisms. These IWBU values are calculated based on 
the porewater concentration and the final chronic value $(F C V)$ as proposed by Di Toro et al. in 2005 (Equation (2), Table 1).

$$
\sum_{i} \frac{M_{i}}{F C V_{i}}=\frac{M_{C u}}{F C V_{C u}}+\frac{M_{P b}}{F C V_{P b}}+\frac{M_{N i}}{F C V_{N i}}+\frac{M_{Z n}}{F C V_{Z n}}+\frac{M_{C d}}{F C V_{C d}}
$$

Table 1. Derived final chronic values from dissolved water concentrations.

\begin{tabular}{cc}
\hline Metal & Freshwater $\boldsymbol{F C V}$ \\
\hline $\mathrm{Cu}$ & $0.960\left[\mathrm{e}^{(0.8545}[\ln (\text { hardness })]^{-1.465)}\right]$ \\
$\mathrm{Pb}$ & $0.791\left[\mathrm{e}^{(1.273}[\ln (\text { hardness })]^{-4.705)}\right]$ \\
$\mathrm{Ni}$ & $0.997\left[\mathrm{e}^{(0.8460}[\ln (\text { hardness })]^{+1.1645)}\right]$ \\
$\mathrm{Zn}$ & $0.986\left[\mathrm{e}^{(0.8473}[\ln (\text { hardness })]^{+0.7614)}\right]$ \\
$\mathrm{Cd}$ & $\mathrm{CF}\left[\mathrm{e}^{(0.7852}[\ln (\text { hardness })]^{-3.490}\right]$ \\
\hline
\end{tabular}

$\overline{\mathrm{CF}}=1.101672-[(\ln$ hardness)(0.041838)] (revised from Di Toro et al., 2005).

For PAHs, the dissolved phase concentrations $\left(C_{d}\right)$ of each nonionic organic contaminant are divided by its corresponding $F C V$ to derive interstitial water toxic units (IWTUs) (Equation (3)). Table 2 shows $C_{d, P A H i, F C V i}$ values for the 16 compounds.

$$
\sum_{i} I W T U_{F C V, 16}=\sum_{i} \frac{C_{d}}{C_{d, P A H i, F C V i}}
$$

Table 2. The final chronic values for the 16 PAHs.

\begin{tabular}{cccc}
\hline Compound & $\boldsymbol{F C V}(\boldsymbol{\mu g} / \mathrm{L})$ & Compound & $\boldsymbol{F C V}(\boldsymbol{\mu g} / \mathrm{L})$ \\
\hline Acenaphthene & 55.85 & Chrysene & 2.042 \\
Acenaphthylene & 306.9 & Dibenz[a,h]anthracene & 0.2825 \\
Anthracene & 20.73 & Fluorene & 39.3 \\
Benzo[a]anthracene & 2.227 & Fluoranthen & 7.109 \\
Benzo[a]pyrene & 0.9573 & Indeno[1,2,3-c,d]pyrene & 0.275 \\
Benzo[b]fluoranthene & 0.6774 & Phenanthrene & 19.13 \\
Benzo[k]fluoranthene & 0.6415 & Pyrene & 10.11 \\
Benzo[g,h,i]perylene & 0.4391 & Naphthalene & 193.55 \\
\hline
\end{tabular}

Source: U.S. EPA (2003) [41].

In sediments in which IWBUs or IWTU is $>1.0$, benthic organisms are not protected and adverse effects may occur. Conversely, if the IWBUs/IWTU is $\leq 1.0$, sediment toxicity due to mixing of contaminants is unlikely.

\section{Results and Discussion}

Four water parameters were routinely monitored during the toxicity testing procedures, including temperature, $\mathrm{pH}$, dissolved oxygen, and conductivity. Since the test was commonly performed under controlled conditions, at constant temperature, water temperature was commonly the least varying factor. The $\mathrm{pH}$, dissolved oxygen, and conductivity are shown in Table 3, before and after exposure. 
Table 3. $\mathrm{pH}$, dissolved oxygen, and conductivity in sediment porewaters during toxicity testing.

\begin{tabular}{|c|c|c|c|c|c|c|}
\hline \multirow[t]{2}{*}{ Site } & \multicolumn{2}{|c|}{$\mathrm{pH}$} & \multicolumn{2}{|c|}{$\begin{array}{l}\text { Dissolved Oxygen } \\
\text { (mg/L) }\end{array}$} & \multicolumn{2}{|c|}{$\begin{array}{l}\text { Conductivity } \\
(\mu \mathrm{mho} / \mathrm{cm})\end{array}$} \\
\hline & Initial & End & Initial & End & Initial & End \\
\hline BK & 7.78 & 8.86 & 5.81 & 4.93 & 16 & 18 \\
\hline YS1 & 8.15 & 8.52 & 4.52 & 5.39 & 576 & 560 \\
\hline YS2 & 8.22 & 8.44 & 4.80 & 5.86 & 1090 & 1100 \\
\hline YS3 & 8.36 & 8.72 & 4.44 & 5.94 & 1040 & 1040 \\
\hline YS4 & 8.68 & 8.69 & 5.52 & 5.83 & 178 & 182 \\
\hline YS5 & 8.34 & 8.80 & 5.43 & 5.85 & 184 & 188 \\
\hline SY1 & 8.02 & 8.45 & 4.73 & 6.46 & 1990 & 1960 \\
\hline SY2 & 8.07 & 8.40 & 3.86 & 5.47 & 1670 & 1730 \\
\hline SY3 & 8.14 & 8.56 & 4.26 & 6.82 & 1210 & 1220 \\
\hline AGD1 & 8.30 & 8.61 & 2.70 & 6.36 & 77 & 73 \\
\hline AGD2 & 8.43 & 8.31 & 4.26 & 5.55 & 84 & 65 \\
\hline DB1 & 7.97 & 8.61 & 3.89 & 5.80 & 1560 & 1610 \\
\hline DB2 & 8.27 & 8.61 & 4.75 & 5.90 & 1710 & 1710 \\
\hline DB3 & 8.35 & 8.59 & 5.44 & 5.71 & 877 & 887 \\
\hline DB4 & 7.82 & 8.30 & 4.64 & 5.18 & 788 & 783 \\
\hline DB5 & 7.90 & 8.60 & 4.86 & 5.59 & 890 & 903 \\
\hline HJ1 & 7.81 & 8.41 & 2.04 & 5.89 & 85 & 92 \\
\hline $\mathrm{HJ} 2$ & 7.76 & 8.51 & 2.16 & 1.62 & 73 & 86 \\
\hline HJ3 & 8.29 & 8.30 & 1.73 & 1.26 & 78 & 80 \\
\hline HJ4 & 8.53 & 8.81 & 1.21 & 1.45 & 90 & 76 \\
\hline HJ5 & 7.89 & 7.84 & 2.28 & 1.29 & 74 & 106 \\
\hline HJ6 & 8.10 & 8.56 & 2.89 & 1.09 & 123 & 72 \\
\hline HJ7 & 8.14 & 8.80 & 1.25 & 1.56 & 1490 & 1690 \\
\hline LK1 & 8.39 & 8.36 & 4.42 & 5.69 & 83 & 56 \\
\hline LK2 & 8.40 & 8.47 & 4.40 & 5.64 & 67 & 56 \\
\hline LK3 & 8.36 & 8.50 & 4.46 & 5.47 & 92 & 83 \\
\hline WR1 & 8.48 & 8.55 & 3.47 & 5.83 & 133 & 105 \\
\hline WR2 & 8.19 & 7.89 & 4.22 & 5.56 & 48 & 50 \\
\hline WR3 & 8.57 & 8.71 & 4.28 & 5.83 & 79 & 69 \\
\hline WR4 & 8.38 & 8.23 & 4.30 & 5.52 & 65 & 50 \\
\hline WR5 & 8.48 & 8.20 & 5.25 & 6.14 & 116 & 107 \\
\hline WR6 & 8.10 & 8.39 & 3.87 & 5.37 & 102 & 86 \\
\hline DG1 & 7.62 & 8.40 & 1.04 & 1.20 & 680 & 660 \\
\hline DG2 & 8.07 & 8.35 & 1.21 & 1.29 & 21 & 24 \\
\hline DG3 & 8.25 & 8.71 & 2.19 & 1.73 & 54 & 37 \\
\hline DG4 & 8.02 & 8.72 & 2.33 & 1.26 & 20 & 24 \\
\hline
\end{tabular}

Houjin river-HJ, Donggang river-DG, Yanyan river-YS, Sanye river-SY, Dianbao river-DB, Agongdian river-AGD, Wuluo river-WR, and Niuchou river-LK.

\subsection{Water Quality Monitoring of Porewater Samples}

The test results showed that the $\mathrm{pH}$ values of all porewater samples were between 7.62 and 8.68 , which approximated a $\mathrm{pH}$ ranging from 6.5 to 8.5 . The dissolved oxygen values of 35 sampling sites ranged from 1.04 to $5.44 \mathrm{mg} / \mathrm{L}$. Vaquer-Sunyer and Duarte [42] stated that most crustaceans begin to show elevated mortality when the dissolved oxygen reaches below $2.45 \pm 0.14 \mathrm{mg} / \mathrm{L}$, whereas dissolved oxygen levels in the rivers of $\mathrm{HJ}$ and DG in 
this study were both lower than $2.45 \mathrm{mg} / \mathrm{L}$ and thus were worthy of further discussion of the physiological effects of dissolved oxygen. Conductivity increased due to an increase in salinity. Sampling sites HJ7 and DG1 were closer to the ocean, and the conductivity was relatively higher here than at the inland sites. In addition, site YS crossed the industrial area, and sites such as DB and SY were adjacent to the factory area. Therefore, discharged sewage led to relatively higher electrical conductivity.

\subsection{Survival Rate of Hyalella azteca Exposed to Whole Sediment Porewater Samples}

In this study, $88 \%$ of the 35 sample stations had adverse effects on aquatic organisms and with this on human health. The survival of the remaining $12 \%$ sites was between $75 \%$ and $90 \%$, showing that the sediment pollutants of eight streams in the southern region had a great variation. The results of 35 survival rates of porewater exposure are shown in Figure 2, demonstrating different potential ecological risks.

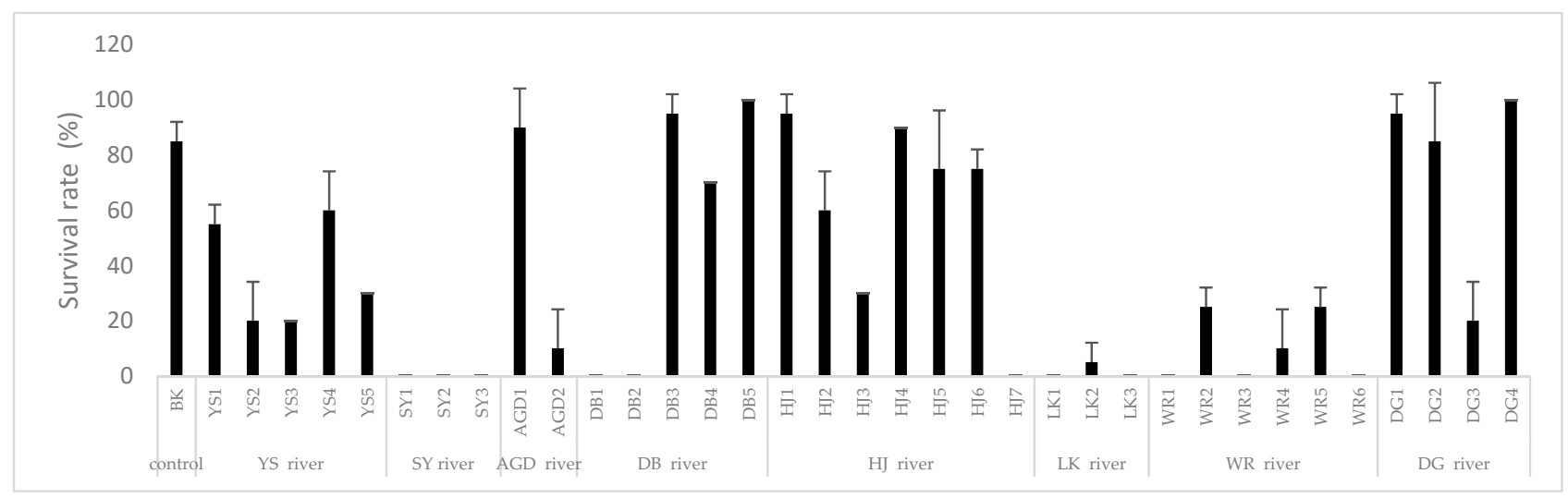

Figure 2. Survival rate of Hyalella azteca exposed to 35 sediment porewater samples in eight river basins. Error bars represent standard deviations $(\mathrm{n}=2)$.

Figure 2 shows the survival rate of $H$. azteca in sediment porewaters. The mean control survival of $H$. azteca in the $48 \mathrm{~h}$ exposures met test acceptability criteria for survival [39,43]. Higher amphipod survival rates $(>80 \%)$ were found at the following sites: DB3, DB5, AGD1, HJ1, HJ4, DG1, DG2, and DG4. All amphipods died in porewaters from sites DB1, DB2, SY1, SY2, SY3, HJ7, LK1, LK3, and WR. This indicates that the Sanye River (sites designated as SY) and Niuchou River (designated as LK) showed acute toxic effects on benthic invertebrates.

It was suggested that if the adjusted survival rate of organisms was less than $75 \%$ this would cause adverse effects on aquatic organisms and human health. If the survival rate was between $75 \%$ and $90 \%$ for aquatic organisms, human health could be harmed and if aquatic organisms showed a survival rate $>90 \%$, human health was certainly affected [40].

\subsection{Toxic Effects of Sediment Porewater on Zebrafish Embryos}

In this research, the effects of 35 sediment porewater samples on the development of zebrafish in different regions of Taiwan were evaluated after four days of exposure. The results of mortality, hatchability, and deformity rate on zebrafish embryos were recorded daily to evaluate the toxic effects of the sediment porewater as shown in Figures 3-5. Embryos of nearly all fertilized eggs hatched on the third day of the general culture and the hatchability reached more than $98 \%$ in cases. In some instances, the control group could also show abnormal development due to physical differences between the organisms. However, the deformity ratio of the control group was low at about $1 \%$. The samples tested were based on the results of mortality and nine sediment porewater samples, HJ7, DB 1 5, and SY 1 3 were classified as being acutely toxic where all zebrafish embryos died after one day of immersion. The toxicity of four samples from YS4, WR1, WR 3, and WR 6 showed the second highest toxicity, which could also be classified as the highest 
toxicity due to the fact that all zebrafish embryos were dead after a two-day exposure. When zebrafish embryos were exposed to porewater samples from HJ3, DG1, LK1, LK2, HJ2, LK3, YS1 3, WR2, WR 4, and WR 5, either all of them died or the survival rate was lower than $20 \%$ on the third day. We classified such porewater samples as moderately toxic. The other 10 porewater samples (HJ1, DG3, HJ5, DG4, YS5, HJ6, AGD1, AGD2, HJ4, and DG2) were classified as less toxic. The survival rate here was still roughly higher than $15 \%$ on the fourth day of exposure. The embryonic development of zebrafish lasted for about 2 days and the main organs of zebrafish were developing thereafter until larval fishes hatched from their eggs. The development of zebrafish was seriously affected by pollutants contained in the porewater samples, causing incomplete development of organs in the fish embryos as shown in Figures 3-5. In terms of deformity, a high deformity ratio was discovered in the moderate toxicity samples HJ3 and YS3. At site HJ3, 78\% of the samples showed deformation while the survival rate was still below $69 \%$ on the second day. Recent research found that there were up to $85 \%$ deformities in the surviving individuals of the porewater sample from YS3. The remaining less toxic samples showed that mortality and deformity rates increased at longer treatment periods. Moreover, the hatching rate was low and showed delays until hatching. Although less toxic samples were classified with low toxicity, they still showed a significant toxic effect compared to the control group.

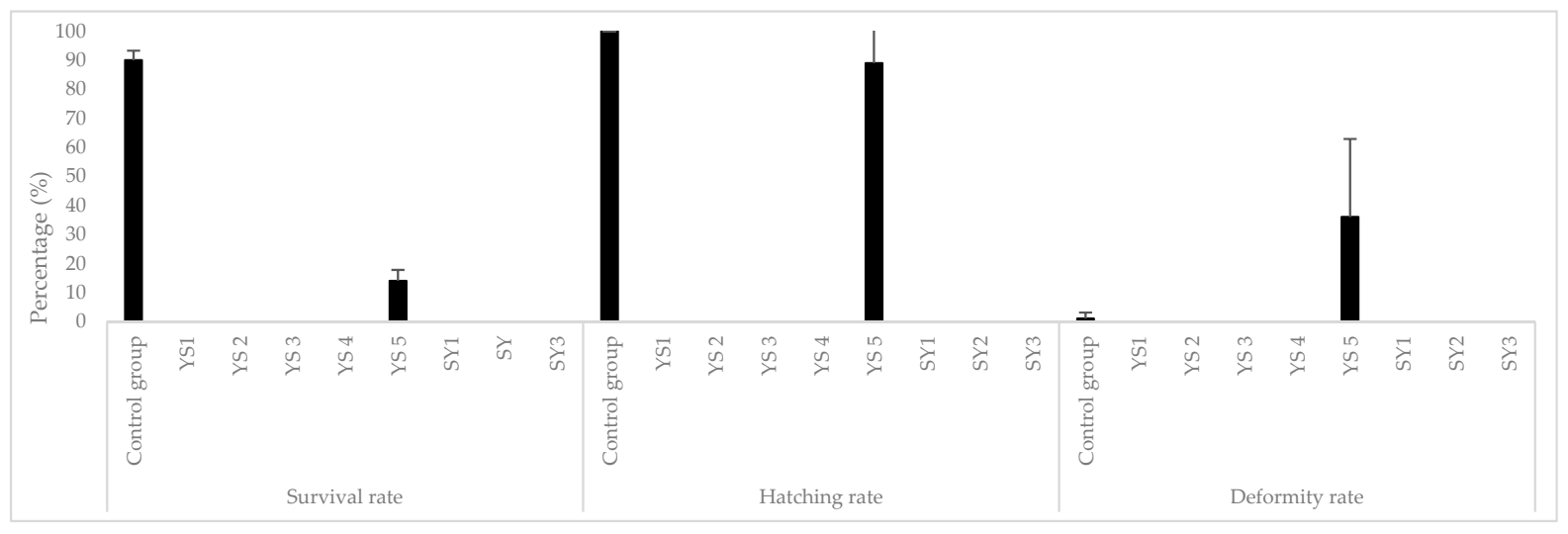

Figure 3. Toxic effects on survival, hatching rate, and deformity rate of zebrafish embryos of river sediment porewater from different sampling sites in Tainan city. Error bars represent standard deviations $(n=3)$.

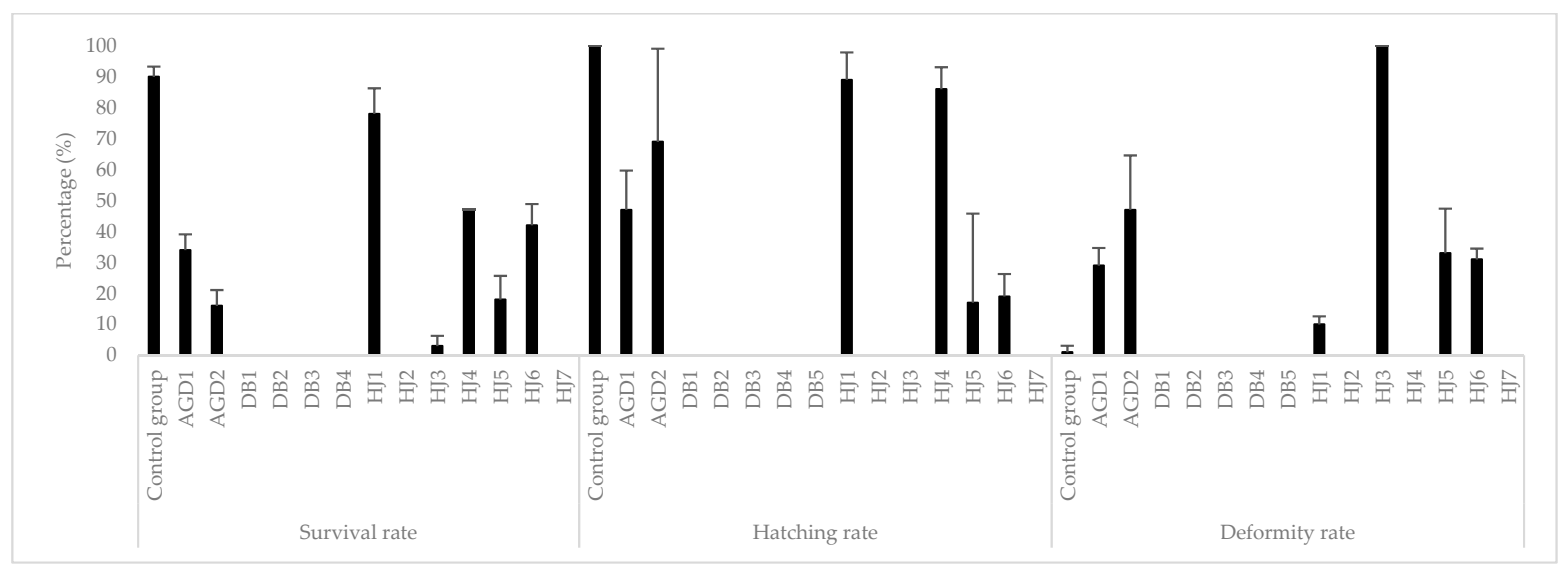

Figure 4. Toxic effects on survival, hatching rate, and deformity rate of zebrafish embryos of river sediment porewater from different sampling sites in Kaohsiung city. Error bars represent standard deviations $(\mathrm{n}=3)$. 


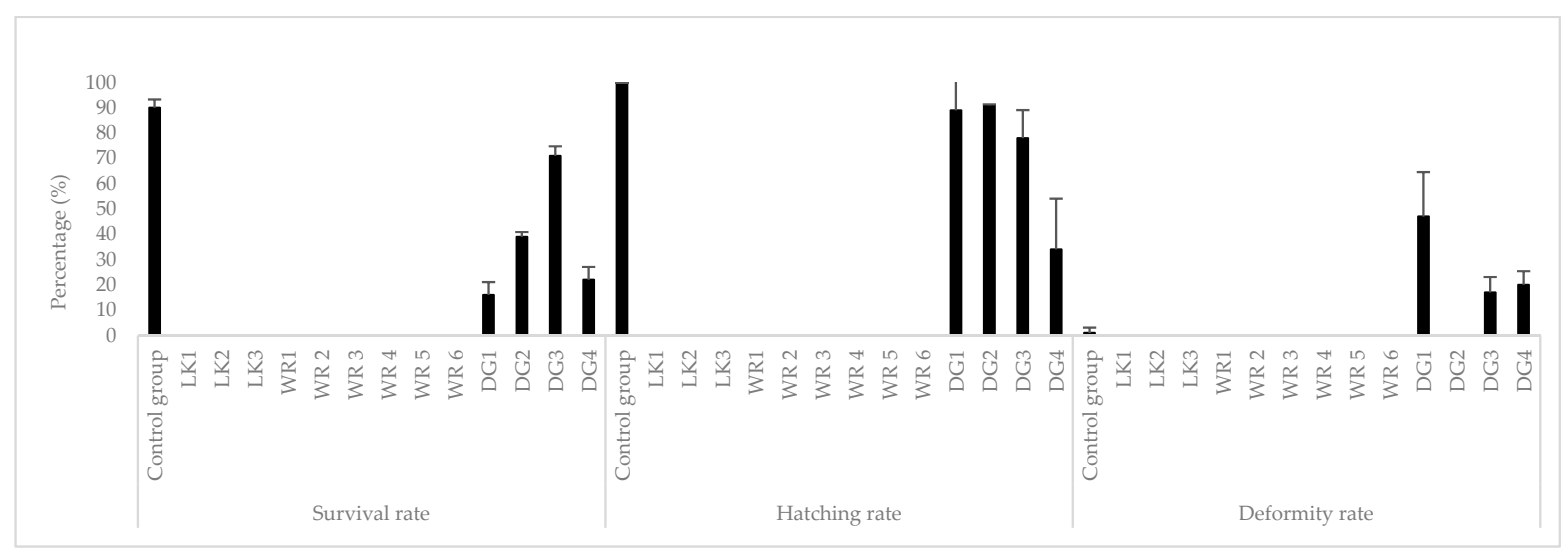

Figure 5. Toxic effects on survival, hatching rate, and deformity rate of zebrafish embryos of river sediment porewater from different sampling sites in Pingtung city. Error bars represent standard deviations $(\mathrm{n}=3)$.

\subsection{Toxic Effects of Sediment Porewater on Zebrafish Embryos}

In general, zebrafish hatch after 2 3 days post-fertilization ( $2 \mathrm{dpf}$ ), when most of the organs are developed. In our study, the morphology of zebrafish was observed on the 2nd and 3rd day of sediment porewater immersion with results shown in Figures S1 and S2. The zebrafish in the control group show normal development on the 2nd day. Their eyes, trunk, and yolk sacs indicate a clear formation of melanin; however, most samples from sediment porewater of different rivers show developmental stagnation (such as sample HJ3-1, HJ3-2, HJ2, HJ3, and HJ5-2) and effects of delay. Deformity of spinal cord and tail curvature could also be observed (sample HJ5-1, DG4-1, DG4-2, YS1-1, WR4-3, and others). The number of melanophores of the control group on the 3rd day increased significantly compared to the 2 nd day sample. The samples treated with sediment porewater not only showed developmental stagnation and delays, some embryos also showed tail deformities and necrosis (such as AGD1-1, AGD1-2, AGD1-3, YS2-1, HJ6-3, HJ5-1, HJ5-3, DG4-1, DG4-2, DG4-3, DG3-1, DG3-2, and DG3-3). Pericardial edema was also found in samples DG1-1, DG4-2, HJ-3, DG3-1, and DG3-3.

\subsection{Toxic Effects on Embryonic Cardiac Function}

The cardiovascular system is the first organ system to form during embryonic development. The circulatory system is also a key factor for embryonic survival. In acute embryonic toxicity testing, the heart rate of hatching zebra fry was determined after the third day. The variations of embryonic heartbeat of zebrafish are shown in Figure 6. The porewater samples DG1, LK2, YS1, and YS2 caused a significant decrease in heartbeat compared to the control group. The average heartbeat rate of zebrafish in the control group was about 185 times per minute (taken as 100\%), while the heartbeat rates were dropping to 133 and 115 per minute in toxic samples from stations YS1 and YS2. There show the most significant effects with heartbeat dropping down to $71 \%$ and $62 \%$. The heartbeat rate of moderately toxic samples (HJ3, LK1, HJ2, LK3, YS3, WR2, WR4, and WR5), cannot be measured due to insufficient fish larvae which were dead or deformed on the third day. The effect of low toxicity (survival ratio was still roughly higher than $15 \%$ on the fourth day of exposure) samples (HJ1, HJ4, DG2, DG3, DG4, HJ5, HJ6, YS6, AGD1, and AGD2) on heart rate was evaluated and the results are shown in Figure 6. Low toxicity samples also caused a significant decrease in heartbeat rate. Compared to the control group, the degree of decline was between $80 \%$ (AGD1) to $93 \%$ (DG4). Overall, the decreasing tendency of the heartbeat rate was less in moderately toxic samples YS1 and YS2. The results showed that both medium toxic and low toxic samples can significantly cause a decrease in heartbeat rate, which indicates that the heart beat and circulatory function of fish generally deteriorated when exposed to sediment leachates of the two rivers. 


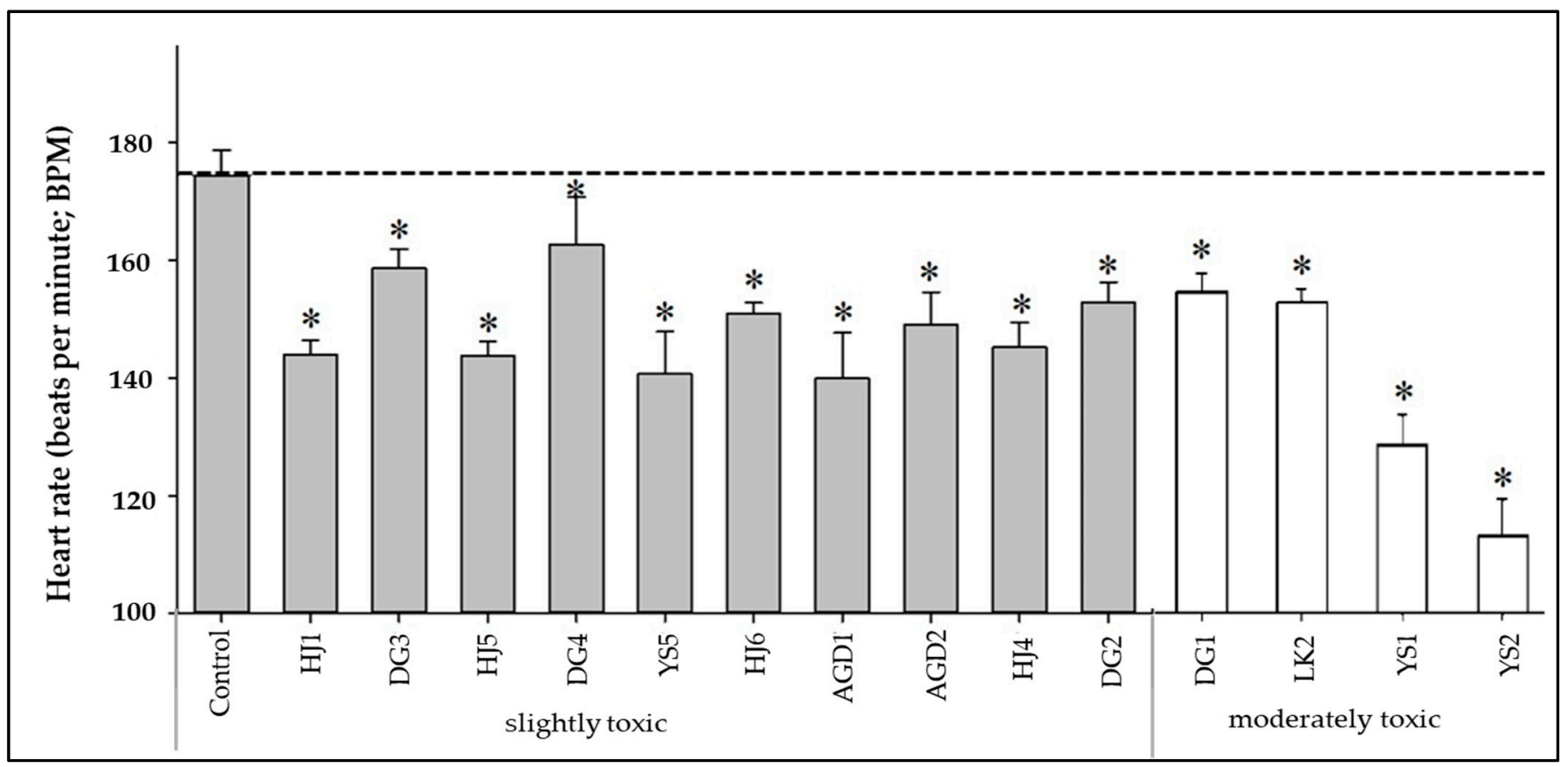

Figure 6. Effect of pollutants from sediment porewater on the heartbeat rate of zebrafish embryos. Hatching rate of zebrafish embryos exposed for $72 \mathrm{~h}$ at sampling stations with slightly toxic and moderately toxic porewaters. Error bars represent the standard deviation of the six zebrafish embryos. ${ }^{*} p<0.05$ indicates significant differences between the control and exposure groups.

\subsection{Comparative Results of PAH Concentrations}

For chemical analysis, naphthalene, benzo(b)fluoranthene, dibenz(a,h)anthracene, and acenaphthalene were not detected in any of the porewater samples. Among the detected PAHs, fluoranthene was the most abundant quantified PAH in the porewater at all stations, followed by pyrene. High concentrations of the B[a]A, CHRY, and FLTH at site $\mathrm{HJ}$ were probably due to the five major industrial pollution sources (refineries, export processing zones, two industrial zones, and plastic manufacturing) found nearby, which bear a large amount of industrial wastewater and household sewage. Site DG1 was surrounded by livestock industries in the region which caused livestock wastewater pollution. The pollution sources in River YS could be related to domestic wastewater and additional wastewater discharge from the Linhai Industrial Zone and surrounding steel plant. Moreover, the mainstream of SY is crossing through two major industrial areas, coupled with discharged wastewater from the livestock industry. Pollution at river DB is due to the metal industry along the river, causing serious metallic and domestic wastewater pollution. These are caused by the major metal surface treatment industry and animal husbandry in the AGD upstream. The main pollution source impact of livestock wastewater on the WR and LK may be related to high concentrations of PAHs. The results of chemical analysis are shown in Table 4.

The $\Sigma$ PAHs in the porewater of the 35 stations ranged from 0.085 to $378 \mu \mathrm{g} / \mathrm{L}$, and the average $\Sigma$ PAHs of the eight streams ranged from $4.807 \pm 5.614$ (AGD river) to $69.846 \pm 151.487$ (WR river).The sampling station with the highest $\Sigma$ PAHs was WR1, followed by HJ1. Studies showed that the concentration of $\Sigma$ PAHs in the porewater ranged between 48.2 and $205.7 \mu \mathrm{g} / \mathrm{L}$ from the Lanzhou Reach of the Yellow River (China). The concentration of $\Sigma$ PAHs detected in the porewater of the Mersey Estuary (UK) ranged from 0.095 to $0.742 \mu \mathrm{g} / \mathrm{L}$ [44]. The concentration range within porewater of Xiamen Harbor (China) was $<1$ to $3548 \mathrm{ng} / \mathrm{L}$ [45]. The total PAHs detected in the Jiulong River Estuary and Western Xiamen Sea, China ranged from 158 to $949 \mu \mathrm{g} / \mathrm{L}$ [46]. Compared to other studies, the concentrations of the 16 PAHs in the porewaters of this study are still slightly higher 
than in other aquatic environments, indicating that the toxicity of the porewater is worthy of a follow-up discussion.

Table 4. Concentrations of 16 PAHs in sediment porewaters.

\begin{tabular}{|c|c|c|c|c|c|c|c|c|c|c|c|c|c|c|c|c|}
\hline Sites & ACE & ACY & ANTH & $\mathbf{B}[\mathbf{a}] \mathbf{A}$ & $\mathbf{B}[\mathbf{a}] \mathbf{P}$ & $B[b] F$ & $B[k] F$ & $B[$ ghi $] P$ & CHRY & $\mathrm{D}[\mathrm{ah}] \mathrm{A}$ & FLU & FLTH & IND & PHEN & PYR & NAP \\
\hline YS1 & ND & ND & ND & 6.686 & ND & ND & ND & ND & 0.988 & ND & ND & 0.178 & ND & ND & 0.084 & ND \\
\hline YS2 & ND & ND & 0.808 & 6.901 & ND & ND & ND & ND & ND & ND & ND & 0.174 & ND & ND & 0.088 & ND \\
\hline YS3 & ND & ND & 0.422 & 6.964 & ND & ND & ND & ND & ND & ND & ND & 0.193 & ND & ND & 0.096 & ND \\
\hline YS4 & ND & ND & 0.384 & 6.691 & ND & ND & ND & ND & 2.289 & ND & ND & 0.18 & ND & ND & 0.086 & ND \\
\hline YS5 & ND & ND & 0.93 & 6.687 & ND & ND & 0.007 & ND & 1.378 & ND & ND & 0.179 & ND & ND & 0.084 & ND \\
\hline SY1 & ND & ND & 0.671 & 6.691 & ND & ND & ND & ND & 1.238 & ND & ND & 0.261 & ND & ND & 0.086 & ND \\
\hline SY2 & ND & ND & 0.647 & ND & ND & ND & 0.001 & ND & ND & ND & ND & ND & ND & ND & 0.084 & ND \\
\hline SY3 & ND & ND & ND & 6.699 & ND & ND & ND & ND & 1.898 & ND & ND & 0.223 & ND & 2.764 & 0.096 & ND \\
\hline AGD1 & ND & ND & 0.794 & 7.329 & ND & ND & ND & ND & ND & ND & ND & 0.284 & ND & 0.282 & 0.088 & ND \\
\hline AGD2 & 0.139 & ND & 0.312 & ND & ND & ND & 0.001 & ND & ND & ND & 0.113 & 0.185 & ND & ND & 0.087 & ND \\
\hline DB1 & ND & ND & 0.364 & 6.882 & 0.168 & ND & ND & ND & 9.056 & ND & ND & 0.239 & ND & ND & ND & ND \\
\hline DB2 & ND & ND & 0.271 & 6.712 & ND & ND & ND & ND & 2.707 & ND & ND & 0.188 & ND & ND & 0.085 & ND \\
\hline DB3 & ND & ND & ND & 6.696 & ND & ND & 0.006 & ND & 0.682 & ND & ND & 0.179 & 0.87 & 5.717 & 0.084 & ND \\
\hline DB4 & ND & ND & ND & ND & ND & ND & ND & ND & ND & ND & 0.113 & 0.189 & 0.238 & 0.237 & 0.095 & ND \\
\hline DB5 & ND & ND & ND & 6.773 & ND & ND & 0.031 & ND & 4.026 & ND & ND & 0.215 & ND & ND & 0.106 & ND \\
\hline HJ1 & 0.155 & ND & 1.122 & 8.604 & ND & ND & 0.89 & ND & 90.095 & ND & 0.11 & 0.364 & ND & 0.575 & 0.09 & ND \\
\hline HJ2 & ND & ND & 0.997 & 7.189 & ND & ND & 0.059 & 0.08 & 1.935 & ND & ND & 0.179 & ND & ND & ND & ND \\
\hline HJ3 & 0.148 & ND & ND & 6.814 & ND & ND & 0.057 & ND & 7.37 & ND & 0.11 & 0.19 & ND & ND & 0.087 & ND \\
\hline HJ4 & ND & ND & 0.771 & ND & ND & ND & 0.001 & ND & ND & ND & 0.113 & 0.178 & ND & 0.243 & 0.093 & ND \\
\hline HJ5 & ND & ND & 0.32 & 6.925 & ND & ND & 0.144 & ND & 18.027 & ND & 0.117 & 0.226 & 0.242 & 0.274 & 0.085 & ND \\
\hline HJ6 & ND & ND & 0.534 & 6.707 & ND & ND & 0.015 & ND & 2.408 & ND & ND & 0.184 & ND & 0.234 & 0.086 & ND \\
\hline HJ7 & ND & ND & 0.232 & 7.71 & ND & ND & 0.382 & ND & 48.618 & ND & ND & 0.277 & ND & 0.351 & 0.089 & ND \\
\hline LK1 & ND & ND & 1.098 & 6.857 & ND & ND & 0.037 & ND & 5.022 & ND & ND & 0.185 & 0.238 & ND & 0.084 & ND \\
\hline LK2 & ND & ND & ND & ND & ND & ND & 0.001 & ND & ND & ND & ND & ND & ND & ND & 0.084 & ND \\
\hline LK3 & ND & ND & 0.201 & 44.305 & ND & ND & 0.165 & ND & 0.247 & ND & ND & 0.25 & ND & 0.312 & 0.089 & ND \\
\hline WR1 & ND & ND & 0.214 & 14.678 & 0.015 & ND & 3.782 & ND & 356.24 & ND & ND & 1.182 & ND & 2.531 & 0.115 & ND \\
\hline WR2 & ND & ND & 0.335 & ND & ND & ND & 0.224 & 0.455 & ND & ND & ND & 0.184 & ND & ND & ND & ND \\
\hline WR3 & ND & ND & 0.266 & 8.748 & ND & ND & ND & ND & ND & ND & ND & 0.218 & 0.249 & ND & 0.099 & ND \\
\hline WR4 & ND & ND & 0.394 & 6.901 & ND & ND & 0.093 & ND & 11.832 & ND & ND & 0.228 & ND & 0.242 & 0.099 & ND \\
\hline WR5 & ND & ND & 0.283 & 6.727 & ND & ND & ND & ND & 1.114 & ND & ND & 0.231 & ND & ND & 0.096 & ND \\
\hline WR6 & ND & ND & 0.56 & ND & ND & ND & ND & ND & 0.251 & ND & ND & 0.187 & ND & 0.217 & 0.087 & ND \\
\hline DG1 & ND & ND & 0.952 & ND & ND & ND & ND & ND & 0.253 & ND & ND & 0.22 & ND & ND & 0.085 & ND \\
\hline DG2 & 0.148 & ND & 0.782 & ND & ND & ND & 0.021 & ND & ND & ND & 0.11 & 1.084 & ND & ND & 0.092 & ND \\
\hline DG3 & ND & ND & 1.212 & ND & ND & ND & 0.001 & ND & ND & ND & 0.116 & 0.173 & ND & ND & 0.085 & ND \\
\hline DG4 & ND & ND & 0.563 & 36.811 & ND & ND & 0.154 & ND & 0.248 & ND & ND & 0.211 & ND & 0.289 & 0.086 & ND \\
\hline
\end{tabular}

Unit: $\mu \mathrm{g} / \mathrm{L}$; ND—not determined; abbreviations were designated as following: naphthalene (NAP), acenaphthylene (ACY), acenaphthene (ACE), fluorene (FLU), phenanthrene (PHEN), anthracene (ANTH), fluoranthene (FLTH), pyrene (PYR), benzo[a]anthracene (B[a]A), chrysene $(\mathrm{CHRY})$, benzo[b]fluoranthene $(\mathrm{B}[\mathrm{b}] \mathrm{F})$, benzo[k]fluoranthene $(\mathrm{B}[\mathrm{k}] \mathrm{F})$, benzo[a]pyrene $(\mathrm{B}[\mathrm{a}] \mathrm{P})$, benzo[g,h,i]perylene $(\mathrm{B}[\mathrm{ghi}] \mathrm{P})$, indeno[1,2,3-c,d]pyrene (IND), and dibenz[a,h]anthracene (D[ah]A).

\subsection{Comparison of Results from PAH Analysis and Biological Survival Rates}

The survival rate of test organisms and the concentration of PAHs were determined, after statistical analysis. The degree of correlation was classified as low when the correlation was \pm 0.3 (between 0.3 and -0.3 ) while moderate and high correlations were \pm 0.3 to $0.6 \pm 0.6$ to 0.9 (between 0.3 and $0.6,-0.3$ to -0.6 ). Since naphthalene, acenaphthene, benzo(b)fluoranthene, dibenz(a,h)anthracene, and acenaphthalene were not detected, the correlation could not be calculated. The biological survival rate showed a low correlation with phenanthrene, anthracene, pyrene, benzo(a) anthracene, chrysene, benzo(b) fluoranthene, and benzo(a) pyrene; medium correlation with fluoranthene and benzo(g,h,i)perylene; and a high correlation with fluorene.

\subsection{Discussion of Trace Metal Concentrations of Sediment Porewater and the Survival Rate of Hyalella azteca}

Table 5 shows heavy metal concentrations in the porewater of sediments of the 35 sites. Test results showed that the concentrations of the trace metals nickel, copper, and lead were mostly below the detection limits. Chromium and zinc were the two most detected metals in sediment porewater. The highest metal concentration for total chromium was detected at sample site LK2; zinc showed the highest concentration at site WR4. 
Table 5. Concentrations of heavy metals in sediment porewaters.

\begin{tabular}{|c|c|c|c|c|c|}
\hline Sites & $\mathrm{Cr}$ & $\mathbf{N i}$ & $\mathrm{Cu}$ & $\mathrm{Zn}$ & $\mathrm{Pb}$ \\
\hline YS1 & 0.017 & ND & ND & 0.02 & ND \\
\hline YS2 & 0.045 & ND & ND & 0.164 & ND \\
\hline YS3 & 0.046 & ND & ND & 0.153 & ND \\
\hline YS4 & 0.005 & ND & ND & 0.102 & ND \\
\hline YS5 & 0.025 & ND & ND & 0.171 & ND \\
\hline DB1 & 0.019 & ND & ND & 0.249 & ND \\
\hline DB2 & ND & ND & ND & 0.027 & ND \\
\hline DB3 & 0.017 & ND & 0.007 & 0.431 & ND \\
\hline DB4 & 0.031 & ND & ND & 0.313 & ND \\
\hline DB5 & 0.038 & ND & ND & 0.939 & ND \\
\hline SY1 & 0.042 & ND & ND & 0.223 & ND \\
\hline SY2 & 0.212 & 0.029 & 0.01 & 0.554 & 0.005 \\
\hline SY3 & 0.183 & 0.022 & ND & 0.574 & ND \\
\hline AGD1 & ND & ND & ND & 1.034 & ND \\
\hline AGD2 & 0.025 & ND & ND & 0.878 & ND \\
\hline HJ1 & 0.009 & ND & ND & 0.065 & ND \\
\hline $\mathrm{HJ} 2$ & ND & ND & ND & 0.191 & ND \\
\hline HJ3 & ND & ND & ND & ND & ND \\
\hline HJ4 & ND & ND & 0.007 & 0.018 & ND \\
\hline HJ5 & ND & ND & ND & ND & ND \\
\hline HJ6 & ND & ND & ND & 0.023 & ND \\
\hline HJ7 & ND & ND & ND & ND & ND \\
\hline LK1 & 0.014 & 0.02 & 0.007 & 0.167 & ND \\
\hline LK2 & 0.149 & 0.185 & ND & 3.333 & ND \\
\hline LK3 & 0.029 & ND & ND & 0.594 & ND \\
\hline WR1 & ND & ND & ND & 0.159 & ND \\
\hline WR2 & ND & ND & ND & 0.041 & ND \\
\hline WR3 & 0.012 & ND & ND & 1.011 & ND \\
\hline WR4 & 0.036 & 0.256 & 0.126 & 3.609 & 0.045 \\
\hline WR5 & ND & ND & ND & 0.016 & ND \\
\hline WR6 & ND & ND & ND & 0.034 & ND \\
\hline DG1 & 0.007 & ND & ND & 0.123 & ND \\
\hline DG2 & 0.009 & ND & ND & 0.406 & 0.007 \\
\hline DG3 & 0.007 & ND & ND & 0.178 & ND \\
\hline DG4 & ND & ND & ND & ND & ND \\
\hline
\end{tabular}

The concentration of heavy metals measured in the porewater of the HJ3 and HJ7 sediment was low; however, we observed a low survival rate of $H$. azteca. A possible reason is that the death of H. azteca may be due to other classes of pollutants, or due to high content of TOC combined with free metal ions, which may decrease their bioavailability and, consequently, reduce their toxicity [47-49]. The literature mentioned that the concentration of heavy metals in porewater is high, not all of which comes from the isolation of heavy metals in sediments, but may be caused by the release of contaminated groundwater [50]. Studies have also pointed out that the copper concentration in the sediment porewater of lakes is positively correlated with organic matter content, but the mortality of chironomid larvae could not be explained by the copper concentration in the porewater [51]. Therefore, it is impossible to determine the cause of the mortality of $H$. azteca based on the concentration of trace metals in the porewater alone.

3.9. Interstitial Water Benchmark Units (IWBUs) and Interstitial Water Toxic Units (IWTUs) Used to Determine Toxicity in Sediment Porewater

In the present study, the survival rates of $H$. azteca and IWBUs were calculated as shown in Figure 7. The results of IWBUs ( $>1$ means toxic) showed that 22 sample sites were toxic and 13 sample sites were not. The results of $\sum$ IWTU showed that $77 \%$ of the sample sites exceeded 1.0 (Figure 8), benthic organisms were not protected, and adverse effects may occur. According to the survival rate of Hyalella azteca, 28 sample sites were 
toxic and 7 sample sites were not. In this study, IWBUs and $\sum$ IWTUs were used to predict the biological toxicity of the porewater of the sediment of eight streams in southern Taiwan, with an accuracy of $79 \%$ and $85 \%$ (number of IWBUs ( $\sum$ IWTUs) ) $>1$ site, and corresponding to the percentage of sites with Hyalella azteca survival rate $<80 \%$, showing that both porewater toxicity calculations for metal and organic compounds can be used as a tool for initial toxicity predictions. When the sample station coincided with IWBUs $>1$ and IWTUs $>1, H$. azteca exposure to the sample also showed toxic effects (survival rate $<80 \%$ ), showing that the combination of IWBUs and IWTUs indicators can more effectively predict the potential toxicity of porewater.

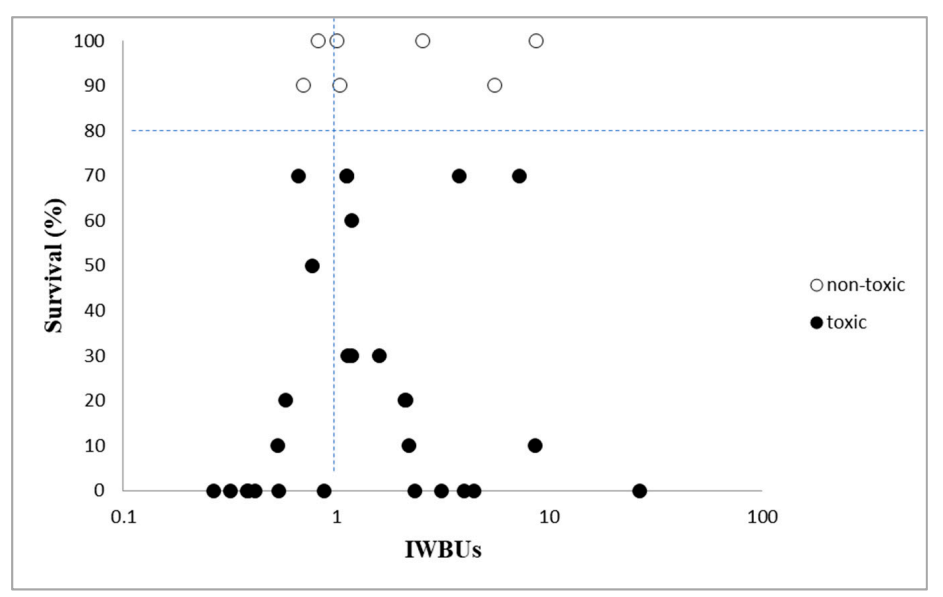

Figure 7. Diagram of interstitial water benchmark units and the Hyalella azteca survival rate correlation.

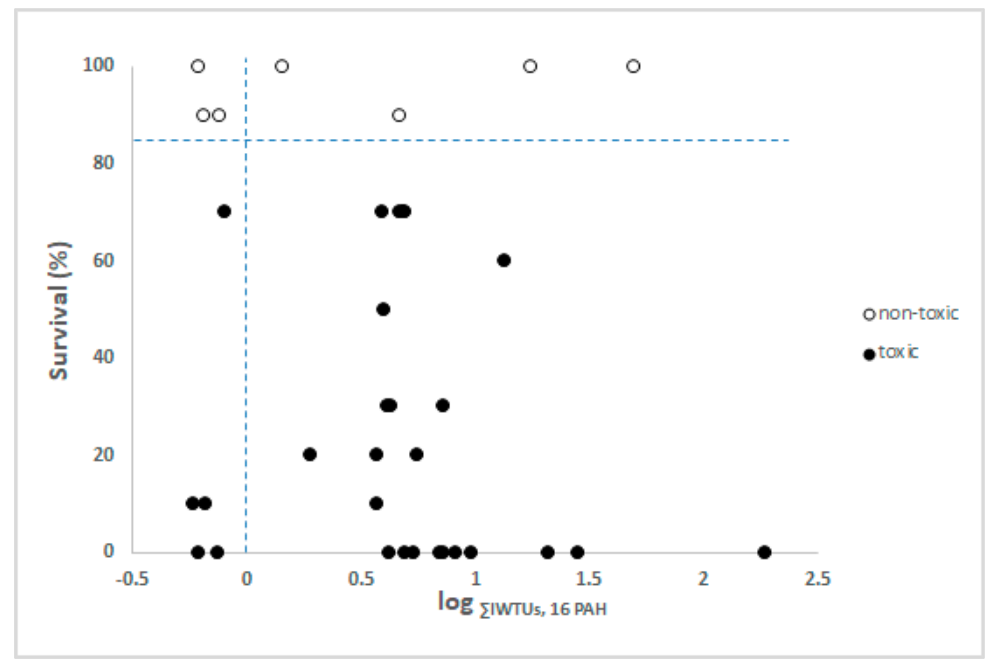

Figure 8. Diagram of interstitial water toxic units and the Hyalella azteca survival rate correlation.

The results of calculating the IWBUs and survival rate of zebrafish embryos in this study showed that when IWBUs $>1$ and $\sum$ IWTUs $>1$ (indicating toxic action), it can accurately predict the toxic effects on zebrafish embryos (Figures 9 and 10). However, when IWBUs $<1$ (indicating non-toxic action), the zebrafish embryos still exhibit toxic effects. This can be explained by the notion that IWBU is mainly for benthic organisms, and embryo exposure belongs to the early life cycle stage of organisms, so the sensitivity is higher than that of later stages [52]. Therefore, the toxicity thresholds for a test with embryos are lower than the set values of the original IWBU. 


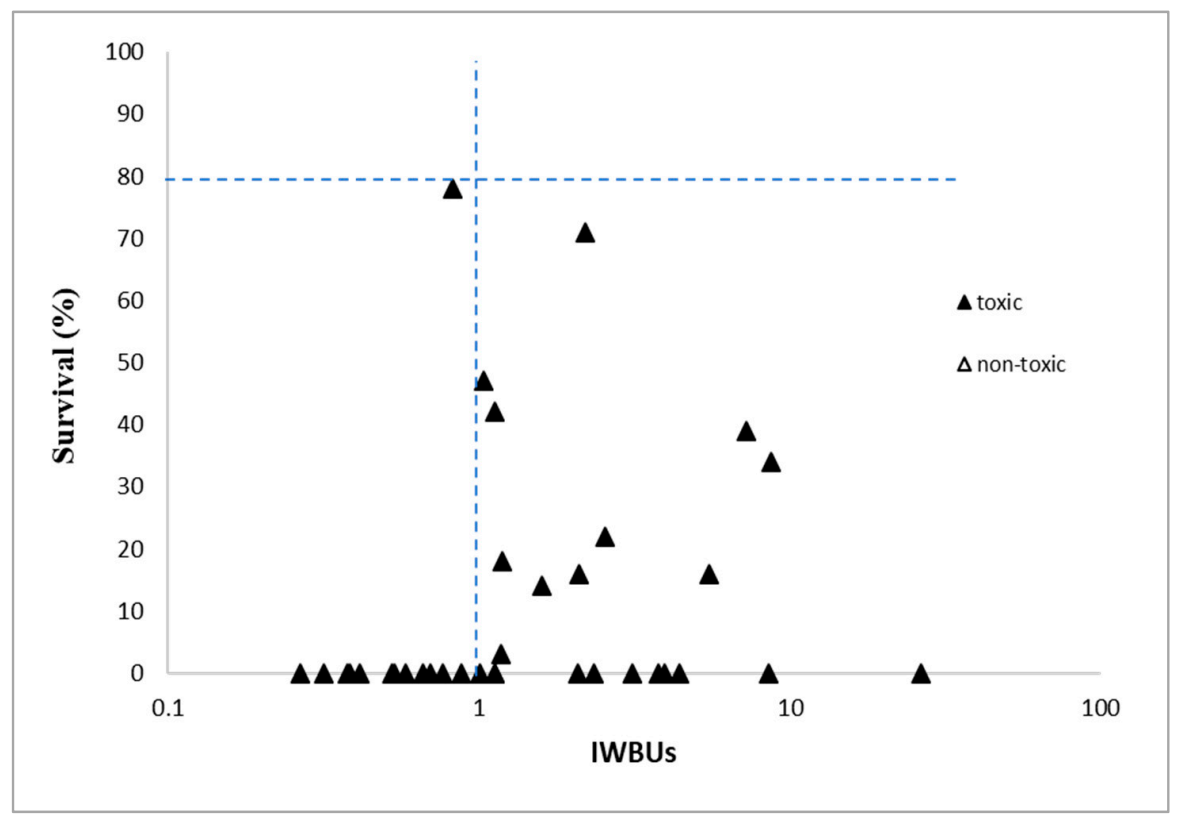

Figure 9. Diagram of the correlation of interstitial water benchmark units and zebrafish embryo survival rate.

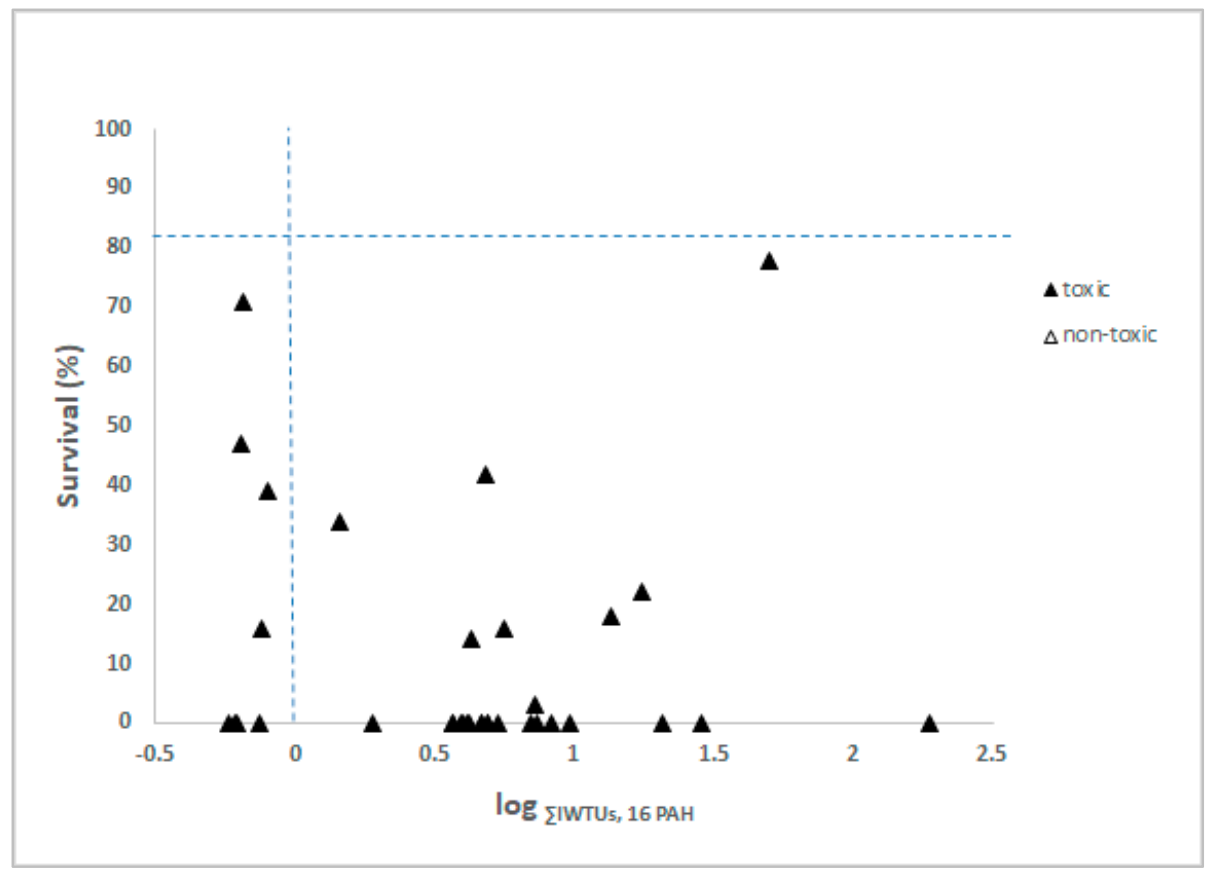

Figure 10. Diagram of the correlation of interstitial water toxic units and zebrafish embryo survival rate.

\section{Conclusions}

The results of our chemical analysis from 35 porewater samples showed that the PAHs naphththalene, acenaphthalene, benzo(b)fluoranthene, dibenz $(\mathrm{a}, \mathrm{h})$ anthracene, and the metal cadmium were not detected at all ampling stations, and the detection frequency of the other 22 compounds, ranging from high to low, was fluoranthene $(94.29 \%)$, pyrene (91.43\%), and zinc (88.57\%). The mortality rate of $H$. azteca exposed to 11 sampling stations (DB1, DB2, SY1, SY2, SY3, HJ7, LK1, LK3, WR1, WR3, and WR6) was $100 \%$ at the end of the porewater toxicity test, and the survival rate was not significantly correlated with the 
6 trace metals and 16 PAHs. In addition, 100\% mortality in the zebrafish embryo toxicity tests was not only observed at the previous 11 sites but also at the other 12 sampling sites (YS1, YS2, YS3, YS4, DB3, DB4, DB5, HJ2, LK2, WR2, WR4, and WR5). This indicates that the porewater of these 11 sites was toxic for both test organisms, and zebrafish embryos were more sensitive than the amphipod H. azteca. Based on the experimental results, the samples show a lack of acute mortality and can also significantly reduce the heartbeat rate of zebrafish embryos. Therefore, it is concluded that the hatching rate of zebrafish embryos provided a more sensitive endpoint than mortality and deformity rate. These results also indicate that the cardiac functioning and circulatory system of fish embryos decreased in a moderate or even low toxic environment. Therefore, it is concluded that the index of heart rate is more sensitive than mortality, and deformity rates of early larvae towards polluted porewater areas of sediments can be affected to some extent. Pearson correlation analysis showed that the concentration of acenaphthene, fluorene, and anthracene had a significant positive correlation with zebrafish embryo survival rate $(p<0.05)$, the heart rate had a significant positive correlation only with fluorene and anthracene $(p<0.001)$, and the deformity rate had a significant positive correlation with anthracene $(p<0.05)$. The chemical analysis and toxicological approach provide a preliminary understanding of the possible risks of dissolved metals and PAHs in sediment porewaters collected from different regions of Taiwan.

Supplementary Materials: The following materials are available online at https:/ /www.mdpi.com/ article/10.3390/app11178021/s1, Table S1. Mobile phase gradient for the UPLC. Table S2. Wavelength programs for fluorescence detection. Table S3. Retention times and method detection limits of the 16 PAHs. Figure S1: Effects of deformities caused by sediment porewater from different locations in Taiwan on zebrafish after 2 days of treatment. The main deformities include spinal cord curvature, cardiac edema, developmental stagnation, tail necrosis. Figure S2: Effects of deformities caused by sediment porewater in different locations in Taiwan on zebrafish after 3 days of treatment. The main deformities include all the above.

Author Contributions: Conceptualization, S.-Y.H. and C.-Y.H.; formal analysis, C.-H.L.; software, M.-C.W.; investigation, Y.-H.T., J.C. and M.-C.W.; data curation, M.-C.W.; writing-original draft preparation, S.-Y.H. and C.-Y.H.; writing-review and editing, H.-U.D.; visualization, J.-H.K.; supervision, C.-Y.H.; project administration, S.-Y.H. and C.-Y.H.; funding acquisition, C.-Y.H. and H.-U.D. All authors have read and agreed to the published version of the manuscript.

Funding: This work was partially supported by the Research Center for Environmental Medicine, Kaohsiung Medical University, Kaohsiung, Taiwan, from The Featured Areas Research Center Program within the framework of the Higher Education Sprout Project by the Ministry of Education (MOE) in Taiwan and by Kaohsiung Medical University Research Center Grant (KMU-TC108A01). A KMU-NPUST collaborative research grant is further acknowledged (NPUST-KMU-110-P010).

Institutional Review Board Statement: Mature wild zebrafish (AB strain wild type) were obtained from the Taiwan Zebrafish Core Facility at Academia Sinica (TZCAS). The experimental protocol was approved (approval no. NPUST-102-041) by the Institutional Animal Care and Use Committee (IACUC) of NPUST.

Informed Consent Statement: Not applicable for this study.

Data Availability Statement: All data are contained within the article or supplementary material.

Acknowledgments: The authors acknowledge the Soil and Groundwater Remediation Fund Management Board of Taiwan for partial financial support of this research. This work was partially supported by the Research Center for Environmental Medicine, Kaohsiung Medical University, Kaohsiung, Taiwan, from The Featured Areas Research Center Program within the framework of the Higher Education Sprout Project by the Ministry of Education (MOE) in Taiwan and by the Kaohsiung Medical University Research Center Grant (KMU-TC108A01). A KMU-NPUST collaborative research grant is further acknowledged (NPUST-KMU-110-P010).

Conflicts of Interest: The authors declare no conflict of interest. 


\section{References}

1. Dahms, H. New Challenges by Toxic Threats to the Environment. Dahms HU Environ. Toxicol. Stud. J. $2018,2,7$.

2. Wu, M.-C.; Dahms, H.-U.; Liu, C.-H.; Hsieh, C.-Y.; Wang, C.-C.; Ho, Z.-Y. Estuarine sediment toxicity testing with an indigenous subtropical amphipod. Mar. Pollut. Bull. 2021, 162, 111797. [CrossRef]

3. Guérin, T.; Chekri, R.; Vastel, C.; Sirot, V.; Volatier, J.-L.; Leblanc, J.-C.; Noël, L. Determination of 20 trace elements in fish and other seafood from the French market. Food Chem. 2011, 127, 934-942. [CrossRef]

4. Dahms, H.U. The grand challenges in marine pollution research. Front. Mar. Sci. 2014, 1, 9. [CrossRef]

5. Dahms, H.U.; Dobretsov, S. Antifouling compounds from marine macroalgae. Mar. Drugs 2017, 15, 265. [CrossRef]

6. Cleveland, D.; Brumbaugh, W.G.; MacDonald, D.D. A comparison of four porewater sampling methods for metal mixtures and dissolved organic carbon and the implications for sediment toxicity evaluations. Environ. Toxicol. Chem. 2017, 36, $2906-2915$. [CrossRef]

7. Simpson, S.; Batley, G. Sediment Quality Assessment: A Practical Guide; Csiro Publishin: Victoria, Australia, 2016.

8. Baran, A.; Urbaniak, M.; Szara, M.; Tarnawski, M. Concentration of dioxin and screening level ecotoxicity of pore water from bottom sediments in relation to organic carbon contents. Ecotoxicology 2021, 30, 57-66. [CrossRef] [PubMed]

9. Ying, G.G.; Rawson, C.A.; Kookana, R.S.; Peng, P.A.; Warne, M.S.; Tremblay, L.A.; Laginestra, E.; Chapman, J.C.; Lim, R.P. Contamination and screening level toxicity of sediments from remediated and unremediated wetlands near Sydney, Australia. Environ. Toxicol. Chem. Int. J. 2009, 28, 2052-2060. [CrossRef] [PubMed]

10. Roig, N.; Nadal, M.; Sierra, J.; Ginebreda, A.; Schuhmacher, M.; Domingo, J.L. Novel approach for assessing heavy metal pollution and ecotoxicological status of rivers by means of passive sampling methods. Environ. Int. 2011, 37, 671-677. [CrossRef] [PubMed]

11. de Castro-Català, N.; Kuzmanovic, M.; Roig, N.; Sierra, J.; Ginebreda, A.; Barceló, D.; Pérez, S.; Petrovic, M.; Picó, Y.; Schuhmacher, M. Ecotoxicity of sediments in rivers: Invertebrate community, toxicity bioassays and the toxic unit approach as complementary assessment tools. Sci. Total Environ. 2016, 540, 297-306. [CrossRef] [PubMed]

12. Cui, L.; Ge, J.; Zhu, Y.; Yang, Y.; Wang, J. Concentrations, bioaccumulation, and human health risk assessment of organochlorine pesticides and heavy metals in edible fish from Wuhan, China. Environ. Sci. Pollut. Res. 2015, 22, 15866-15879. [CrossRef] [PubMed]

13. Dahms, H.-U.; Won, E.-J.; Kim, H.-S.; Han, J.; Park, H.G.; Souissi, S.; Raisuddin, S.; Lee, J.-S. Potential of the small cyclopoid copepod Paracyclopina nana as an invertebrate model for ecotoxicity testing. Aquat. Toxicol. 2016, 180, 282-294. [CrossRef] [PubMed]

14. Tzoraki, O.; Karaouzas, I.; Patrolecco, L.; Skoulikidis, N.; Nikolaidis, N. Polycyclic aromatic hydrocarbons (PAHs) and heavy metal occurrence in bed sediments of a temporary river. Water Air Soil Pollut. 2015, 226, 1-19. [CrossRef]

15. Lei, P.; Zhang, H.; Shan, B.; Zhang, B. Distribution, diffusive fluxes, and toxicity of heavy metals and PAHs in pore water profiles from the northern bays of Taihu Lake. Environ. Sci. Pollut. Res. 2016, 23, 22072-22083. [CrossRef]

16. Subashchandrabose, S.R.; Wang, L.; Venkateswarlu, K.; Naidu, R.; Megharaj, M. Interactive effects of PAHs and heavy metal mixtures on oxidative stress in Chlorella sp. MM3 as determined by artificial neural network and genetic algorithm. Algal Res. 2017, 21, 203-212. [CrossRef]

17. Hartzell, S.E.; Unger, M.A.; Vadas, G.G.; Yonkos, L.T. Evaluating porewater polycyclic aromatic hydrocarbon-related toxicity at a contaminated sediment site using a spiked field-sediment approach. Environ. Toxicol. Chem. 2018, 37, 893-902. [CrossRef]

18. Zhang, C.; Shan, B.; Tang, W.; Wang, C.; Zhang, L. Identifying sediment-associated toxicity in rivers affected by multiple pollutants from the contaminant bioavailability. Ecotoxicol. Environ. Saf. 2019, 171, 84-91. [CrossRef]

19. Chen, C.-F.; Ju, Y.-R.; Su, Y.-C.; Lim, Y.C.; Kao, C.-M.; Chen, C.-W.; Dong, C.-D. Distribution, sources, and behavior of PAHs in estuarine water systems exemplified by Salt River, Taiwan. Mar. Pollut. Bull. 2020, 154, 111029. [CrossRef]

20. Valentina, P.; Michele, M.; Tommaso, G.; Letizia, M.; Laura, M.M.; Francesca, M.; Adriano, S.; Augusto, S.A.; Cristina, M. Sediment Contamination by Heavy Metals and PAH in the Piombino Channel (Tyrrhenian Sea). Water 2021, 13, 1487. [CrossRef]

21. Blanco, S.; Bécares, E. Are biotic indices sensitive to river toxicants? A comparison of metrics based on diatoms and macroinvertebrates. Chemosphere 2010, 79, 18-25. [CrossRef]

22. Shu, Y.Y.; Lee, M.R. Development of the Analysis method of Nitrated-Polycyclic Aromatic Hydrocarbons in Diesel Exhaust Particulates (2/2); EPA-97-E3S2-02-01; EPA Environmental Inspection: Taoyuan, Taiwan, 2008.

23. Inam, E.; Offiong, N.-A.; Essien, J.; Kang, S.; Kang, S.-Y.; Antia, B. Polycyclic aromatic hydrocarbons loads and potential risks in freshwater ecosystem of the Ikpa River Basin, Niger Delta-Nigeria. Environ. Monit. Assess. 2016, 188, 49. [CrossRef]

24. Ali, M.U.; Siyi, L.; Yousaf, B.; Abbas, Q.; Hameed, R.; Zheng, C.; Kuang, X.; Wong, M.H. Emission sources and full spectrum of health impacts of black carbon associated polycyclic aromatic hydrocarbons (PAHs) in urban environment: A review. Crit. Rev. Environ. Sci. Technol. 2020, 51, 857-896. [CrossRef]

25. Ramesh, A.; Archibong, A.E.; Hood, D.B.; Guo, Z.; Loganathan, B.G. Global environmental distribution and human health effects of polycyclic aromatic hydrocarbons. In Global Contamination Trends of Persistent Organic Chemicals; Lam, P.K.S., Loganathan, B.G., Eds.; CRC Press: Boca Raton, FL, USA, 2011; pp. 97-126.

26. Sfakianakis, D.; Renieri, E.; Kentouri, M.; Tsatsakis, A. Effect of heavy metals on fish larvae deformities: A review. Environ. Res. 2015, 137, 246-255. [CrossRef] 
27. Ikue, G.S.; Monanu, M.O.; Onuah, C.L. Bioaccumulation of polycyclic aromatic hydrocarbons in tissues (gills and muscles) of (catfish) Chrysichthys nigrodidatatus from crude oil polluted water of Ogoniland, river state, Nigeria. J. Appl. Life Sci. Int. 2016, 6, 1-6. [CrossRef]

28. Rotondo, L.; Temporetti, P.; Mora, V.; Baffico, G.; Beamud, G.; Diaz, M.; Pedrozo, F. Effects of lake sediment contamination by PAHs on nutrients and phytoplankton in Vaca Muerta, Neuquén, Argentina. Environ. Earth Sci. 2021, 80, 1-13. [CrossRef]

29. ATSDR. Toxicology Profile for Polyaromatic Hydrocarbons; CRC Press: Boca Raton, FL, USA, 2005.

30. Wang, B.-R.; Dahms, H.-U.; Wu, M.-C.; Jhuo, N.-J.; Hsieh, C.-Y. After remediation-Using toxicity identification evaluation of sediment contamination in the subtropical Erren river basin. Chemosphere 2021, 262, 127772. [CrossRef]

31. Vardhan, K.H.; Kumar, P.S.; Panda, R.C. A review on heavy metal pollution, toxicity and remedial measures: Current trends and future perspectives. J. Mol. Liq. 2019, 290, 111197. [CrossRef]

32. Raffa, C.M.; Chiampo, F.; Shanthakumar, S. Remediation of Metal/Metalloid-Polluted Soils: A Short Review. Appl. Sci. 2021, 11, 4134. [CrossRef]

33. Hsieh, H.-Y.; Huang, K.-C.; Cheng, J.-O.; Lo, W.-T.; Meng, P.-J.; Ko, F.-C. Environmental effects on the bioaccumulation of PAHs in marine zooplankton in Gaoping coastal waters, Taiwan: Concentration, distribution, profile, and sources. Mar. Pollut. Bull. 2019, 144, 68-78. [CrossRef]

34. Sonone, S.S.; Jadhav, S.; Sankhla, M.S.; Kumar, R. Water contamination by heavy metals and their toxic effect on aquaculture and human health through food Chain. Lett. Appl. NanoBioSci. 2020, 10, 2148-2166. [CrossRef]

35. Stamatelopoulou, A.; Dasopoulou, M.; Bairachtari, K.; Karavoltsos, S.; Sakellari, K.; Maggos, T. Contamination and Potential Risk Assessment of Polycyclic Aromatic Hydrocarbons (PAHs) and Heavy Metals in House Settled Dust Collected from Residences of Young Children. Appl. Sci. 2021, 11, 1479. [CrossRef]

36. Yi, Y.; Yang, Z.; Zhang, S. Ecological risk assessment of heavy metals in sediment and human health risk assessment of heavy metals in fishes in the middle and lower reaches of the Yangtze River basin. Environ. Pollut. 2011, 159, 2575-2585. [CrossRef] [PubMed]

37. Dahms, H.-U.; Schizas, N.V.; James, R.A.; Wang, L.; Hwang, J.-S. Marine hydrothermal vents as templates for global change scenarios. Hydrobiologia 2018, 818, 1-10. [CrossRef]

38. Yu, Z.; Yin, D.; Zhang, J. Sex-dependent effects of sulfamethoxazole exposure on pro-/anti-oxidant status with stimulation on growth, behavior and reproduction in the amphipod Hyalella azteca. Environ. Pollut. 2019, 244, 398-404. [CrossRef]

39. USEPA. Methods for Measuring the Toxicity and Bioaccumulation of Sediment-Associated Contaminants with Freshwater Invertebrates, 2nd ed.; USEPA: Duluth, MN, USA; Washington, DC, USA, 2000.

40. USEPA. The Incidence and Severity of Sediment Contamination in Surface Waters of the United States, National Sediment Quality Survey; Office of Science and Technology, Standards and Health Protection Divisio: Washington, DC, USA, 2004.

41. USEPA. Procedures for the Derivation of Equilibrium Partitioning Sediment Benchmarks (ESBs) for the Protection of Benthic Organisms: PAH Mixtures; United States Environmental Protection Agency, Office of Research and Development: Washington, DC, USA, 2003.

42. Vaquer-Sunyer, R.; Duarte, C.M. Thresholds of hypoxia for marine biodiversity. Proc. Natl. Acad. Sci. USA 2008, 105, 15452-15457. [CrossRef]

43. ASTM. Standard test method for measuring the toxicity of sediment-associated contaminants with freshwater invertebrates. In ASTM Annual Book of Standards; ASTM: Philadelphia, PA, USA, 2010; p. E1706-05.

44. King, A.; Readman, J.; Zhou, J. Determination of polycyclic aromatic hydrocarbons in water by solid-phase microextraction-gas chromatography-mass spectrometry. Anal. Chim. Acta 2004, 523, 259-267. [CrossRef]

45. Zhou, J.; Hong, H.; Zhang, Z.; Maskaoui, K.; Chen, W. Multi-phase distribution of organic micropollutants in Xiamen Harbour, China. Water Res. 2000, 34, 2132-2150. [CrossRef]

46. Maskaoui, K.; Zhou, J.; Hong, H.; Zhang, Z. Contamination by polycyclic aromatic hydrocarbons in the Jiulong River estuary and Western Xiamen Sea, China. Environ. Pollut. 2002, 118, 109-122. [CrossRef]

47. Burto, G.A., Jr.; Nguyen, L.T.; Janssen, C.; Baudo, R.; McWilliam, R.; Bossuyt, B.; Beltrami, M.; Green, A. Field validation of sediment zinc toxicity. Environ. Toxicol. Chem. Int. J. 2005, 24, 541-553. [CrossRef]

48. Ingersoll, C.; MacDonald, D.; Brumbaugh, W.; Johnson, B.T.; Kemble, N.; Kunz, J.; May, T.; Wang, N.; Smith, J.; Sparks, D. Toxicity assessment of sediments from the Grand Calumet River and Indiana Harbor Canal in northwestern Indiana, USA. Arch. Environ. Contam. Toxicol. 2002, 43, 156-167. [CrossRef]

49. Spencer, K.; Dewhurst, R.; Penna, P. Potential impacts of water injection dredging on water quality and ecotoxicity in Limehouse Basin, River Thames, SE England, UK. Chemosphere 2006, 63, 509-521. [CrossRef] [PubMed]

50. Besser, J.M.; Brumbaugh, W.G.; Ingersoll, C.G. Characterizing toxicity of metal-contaminated sediments from mining areas. Appl. Geochem. 2015, 57, 73-84. [CrossRef]

51. Call, D.J.; Polkinghorne, C.N.; Markee, T.P.; Brooke, L.T.; Geiger, D.L.; Gorsuch, J.W.; Robillard, K.A. Silver toxicity to Chironomus tentans in two freshwater sediments. Environ. Toxicol. Chem. Int. J. 1999, 18, 30-39. [CrossRef]

52. Mohammed, A. Why are early life stages of aquatic organisms more sensitive to toxicants than adults. New Insights Toxic. Drug Test. 2013, 49-62. [CrossRef] 